\title{
Normatividad, justicia y educación. A propósito de la vinculación entre filosofía de la educación e investigación educativa
}

\author{
Andrea Díaz
}

\section{Resumen}

El vínculo entre filosofía de la educación e investigación educativa no ha sido suficientemente revisado y problematizado. En el campo de las ciencias de la educación éste fue planteado en términos antagónicos, o bien asumiendo la filosofía la tarea de fundamentar el conocimiento empírico de las ciencias. Desde una posición de Teoría Crítica es necesario reconstruir el lazo que existe entre teoría normativa y ciencia social, especialmente cuando se trata de abordar un objeto de complejidad práctica, como es la educación. Focalizaremos este tema en el debate sobre la justicia social en el ámbito educacional, porque en él se entrelaza la producción de conocimiento de la investigación educativa con definiciones normativas propias de la filosofía política. Por último, proponemos confrontar esta perspectiva con estudios sobre justicia educativa realizados recientemente en Argentina. Aun cuando muchos de ellos hacen referencia a autores y debates de la Teoría Crítica, el análisis no se realiza estrictamente desde dicha perspectiva, en especial por el modo en que se construye la relación entre normatividad y producción de conocimiento académico.

Palabras clave: Filosofía de la educación. Investigación educativa. Justicia. Normatividad. Teoría crítica. 


\section{Presentación}

Un primer acercamiento al estado del arte de la investigación educativa en nuestro medio permitiría constatar la escaza presencia del abordaje filosófico. Se ha investigado extensamente, con abordajes teóricos diversos y desde el amplio espectro de las Ciencias de la Educación, sobre las formas de subjetivación producidas por los procesos de escolarización, la dinámica de las instituciones educativas, las prácticas de enseñanza y aprendizaje, los procedimientos de evaluación, las políticas públicas del sector educativo, los procesos de socialización y de inclusión ciudadana, entre otros. Sin embargo, la mirada filosófica no siempre está presente, o bien aparece relegada a ciertos temas que requerirían la experticia del filósofo, tal es el caso de la educación moral, ética y formación ciudadana, o la educación en valores.

En este contexto, el tema que convoca el dossier invita a problematizar el sentido mismo de la relación que enlaza a la filosofía de la educación con la investigación educativa. Situadas en dominios que la tradición cientificista del positivismo se esforzó por entender como antagónicos, el carácter normativo de la filosofía pone distancia frente a un conocimiento que busca explicar las prácticas sociales desde el supuesto incontrovertible que le reporta dar cuenta de un hecho objetivo.

También la filosofía, al asumir la fundamentación del conocimiento producido por las ciencias de la educación, contribuyó a profundizar esta distancia. Este rol es ejercido de formas diversas, así al dar cuenta de la coherencia entre los supuestos y los principios de las teorías científicas, o al aportar modelos normativos que funcionan como antropología filosófica, o cuando colabora estableciendo finalidades educativas. Lo cierto es que este camino fue transitado por corrientes de neto corte metafísico -por ejemplo, el espiritualismo pedagógico-, como por aquellas perspectivas que buscaron distanciarse de él, tal es el caso de los enfoques analíticos en teoría de la educación.

Esta distancia aflora en la extrañeza mutua que revelan preguntas del tipo ¿se investiga en filosofía de la educación? ¿Qué reporta la filosofía de la educación a la investigación educativa? Subyace en ellas una forma de comprender la investigación que recela a priori de todo intento normativo, al anclarse exclusivamente en lo empírico como sustrato de objetividad; en el campo educacional este patrón enlaza recepciones ideológicamente disímiles, que abrevan tanto en el positivismo como en ciertos enfoques críticos provenientes del marxismo, pero que configuran un patrón epistémico objetivista y representacional.

En ellas, el vínculo entre filosofía de la educación e investigación educativa queda subsumido a dos posibilidades, de poca fecundidad interpretativa como se 
intentará demostrar. La primera, cuando la presencia de esta relación se establece asumiendo la filosofía el papel de dadora de fines, valores y concepciones apriorísticas (de hombre, vida, libertad, etc.) que funcionan como supuestos epistémicos. La segunda, cuando se proclama la ausencia de este vínculo porque el conocimiento que produce la investigación educativa lo exige como condición de cientificidad y marca de ruptura con el normativismo, señera de una objetividad construida exclusivamente de modo factual.

Sin embargo, no basta conjurar el normativismo para desembarazarse de él. El propio derrotero de las humanidades y de las ciencias sociales puede ser leído desde esta clave, esto es, cómo resuelven las ciencias su propia constitución como campo disciplinar en la ruptura que hacen con la filosofía. Una rápida mirada a las discusiones teóricas del S XIX trae a escena no solo al positivismo, sino también el intenso debate con el historicismo que eclipsó gran parte de la teoría social posterior. Su eco puede encontrarse en los reparos epistemológicos de Foucault frente a la historia de las ideas, o en las lecturas que, a la sombra de Durkheim, realiza Bourdieu sobre el oficio del sociólogo, por nombrar dos autores ampliamente referenciados en la investigación educativa.

Con todo, nuestro objetivo en relación al tema es rehabilitar el lazo entre filosofía e investigación educativa al tiempo que revisar el modo en que ambas se vinculan. Esto supone, retomar el vínculo entre filosofía de la educación y conocimiento como un elemento central para explicar e interpretar las acciones pedagógicas. La defensa de la normatividad la realizaremos desde una doble vía. Por un lado, desde una perspectiva pedagógica que considera a la educación como objeto práctico, por lo que su interrogación y problematización está atravesada por esta espesura ético política. Por otro, una mirada de Teoría Crítica, que dota de un sentido normativo específico a esa práctica, pero que haremos extensiva a la forma de entender la filosofía y la producción de conocimiento.

Esta doble perspectiva nos permitirá reconstruir el vínculo entre filosofía de la educación e investigación educativa tomando como parangón el que en términos de Teoría Crítica se establece entre teoría normativa y ciencia social. Desde allí, nos proponemos dialogar críticamente con apropiaciones teóricas e investigaciones empíricas que expresan de forma diferente esta misma relación, a propósito de la justicia educativa. 


\section{La educación como cuestión práctica: la necesidad de un enfoque normativo}

La extrañeza que expresa la filosofía frente a la facticidad moral y el recelo de la ciencia frente a la normatividad sugerida por la filosofía, hace necesario precisar algo que el propio desarrollo de la investigación educativa parece haber dejado atrás. Porque si de recuperar la normatividad se trata, lo primero que debemos recordar es que lo educativo configura su propio sentido formativo desde una normatividad que se construye en la vinculación estrecha con la trama histórico-social.

Considerar la educación como cuestión práctica supone subrayar la espesura ética y política de esta acción, recuperando una tradición que se manifiesta a lo largo de la historia en los ideales pedagógicos de Paideia, Humanitas y Bildung. Cada uno de éstos se inscribe en un contexto histórico-político particular, sin embargo, se amalgaman en compartir el sentido de la educación como formación del hombre en la comunidad y el tiempo que habita. En su acepción moderna, la formación hace referencia al proceso por el cual la subjetividad se construye a sí misma, en la tensión permanente entre individuación y socialización, coacción y libertad, disciplina y autonomía (GOERGEN, 2009; CULLEN, 2004).

En un artículo del 2013 titulado "La educación y el espacio público democrático: un capítulo descuidado en la Filosofía Política", Axel Honneth recuerda la fuerte ligazón que los pedagogos modernos traban entre educación y formación ciudadana, ocupando la escuela un lugar destacado en la formación del espacio público democrático. Según el filósofo, la Pedagogía ha sido comprendida como:

[...] una hermana gemela de la teoría de la democracia, porque sin instrucciones equilibradas sobre cómo despertar en el niño al mismo tiempo la capacidad de cooperación y la iniciativa moral propia no parecía explicable lo que se quería decir cuando se hablaba de acción conjunta en la autodeterminación democrática; la idea del «buen ciudadano» no era una fórmula vacía o un adorno de los discursos políticos, sino un desafío práctico ante el que había que dar la talla por medio de ensayos teóricos y la experimentación de formas de escuela y métodos didácticos apropiados (HONNETH, 2013, p. 379).

El desarrollo de los saberes que estructuran el campo de las Ciencias de la Educación ha ido relegando, progresivamente, aquellas cuestiones teóricas de la educación que eran objeto de disciplinas como la pedagogía y la filosofía de la educación. A la desatención que según Honneth la filosofía política hace de esa relación, podemos agregar el extrañamiento hermenéutico, la distancia que las Ciencias de la Educación tomaron de la idea de formación y de su horizonte de comprensión. La formación expresa un proceso de transformación y emancipación de un estado inicial, intencionalmente direccionado, que se realiza por la mediación intersubjetiva de instituciones sociales (FLICKINGER, 2009; CULLEN, 2004). 
El carácter práctico de la interrogación, lo que se llama la espesura ético política de la educación como acción (CULLEN, 2004; SIMONS; MASSCHELEIN, 2014), hace del propio lugar de enunciación un espacio teórico pero también público-político, y por ello, sujeto a interpretaciones, tensiones y debates. En el presente trabajo, este horizonte hermenéutico, el lugar de enunciación e interrogación, está circunscripto a la tradición de Teoría Crítica.

La elección de esta opción teórico política se fundamenta en que esta tradición se ha mostrado prolífica al realizar un diagnóstico crítico, con sentido emancipatorio, del presente. Asimismo, la Teoría Crítica ha explorado ampliamente la vinculación entre filosofía y ciencias sociales, buscando alternativas teórico metodológicas ya que requiere de una concepción normativa capaz de comportarse críticamente. Esta opción nos permite, entonces, reconstruir una concepción normativa capaz de develar en los procesos de reproducción social los elementos de una racionalidad existente pero insuficientemente explorada, un punto de vista crítico emergente de la práctica de los propios actores sociales (CELIKATES, 2012). Esto es, siguiendo el principio teórico metodológico de trascendencia inmanente, una concepción normativa anclada en la dinámica de las prácticas sociales que se comporte como parámetro de diagnóstico crítico y de emancipación del presente.

Desde esta perspectiva, analizaremos investigaciones recientes sobre justicia social en el ámbito educacional que recuperan lecturas y aportes de la Teoría Crítica. Dado que las mismas, además, se presentan como situadas y diseñadas especialmente para Argentina, incluiremos un breve recorrido histórico sobre la emergencia del tema en los marcos normativos de la legislación educativa, y en el desarrollo teórico-empírico de la investigación educativa.

\section{La investigación educativa y la construcción de un modelo de justicia educativa}

Las ideas de justicia e igualdad trazan una fuerte comunión en la tradición de educación pública de Argentina. Este modelo fundante es el punto de partida de gran parte de los diagnósticos y propuestas de reformulación que actualmente se postulan sobre el tema. Así lo expresan Veleda, Rivas y Mezzadra:

[...] el modelo de justicia que se propicia no comienza de cero, sino que retoma y revisa las herencias y las conquistas del sistema educativo argentino a la luz de las posibilidades y los desafíos del presente. Dado que se orienta hacia la acción de la política educativa en el concierto federal, es preciso partir de su historia para contextualizar la propuesta, comprender mejor los obstáculos actuales e identificar los criterios de justicia utilizados en el pasado (2011, p. 20). 
Con esa intención, proponemos un breve recorrido histórico a fin de señalar las concepciones de justicia e igualdad en los marcos normativos de la educación pública, y en las producciones de la investigación educativa. ${ }^{1}$

a) Las ideas de igualdad, equidad y justicia social en la educación argentina.

Un rasgo distintivito de la educación escolar en Argentina es su temprana estructuración en la década de 1880, inmediata a la conformación del Estado-Nación, como sistema de instrucción pública, de carácter centralizado y estatal (PUIGGRÓS, 1990). Enmarcada en la proclama de fundar "una Nación para el Estado argentino", el sistema de educación fue el encargado de formar al ciudadano; educar al soberano revela así que el vínculo entre educación y sociedad se estructuró asumiendo la educación pública una función política (TEDESCO, 1986).

En este contexto se promulga en 1884, luego de un extenso y rico debate en el Congreso de la Nación, la Ley № 1420 de Educación Pública Común. Esta norma fundacional de la larga tradición de educación pública en Argentina, viene a garantizar el derecho a la educación que había sido reconocido por la Constitución Nacional de 1853 en su artículo 14, y establece como principios de la educación básica la obligatoriedad, gradualidad, universalidad, laicidad y gratuidad.

Como señala Dussel, la idea de igualdad se instala e impulsa a través de esta imagen de educación común: "Todos debían ser socializados de la misma forma, sin importar sus orígenes nacionales, la clase social, su condición masculina o femenina o su religión, y esta forma de escolaridad fue considerada un terreno 'neutro', 'universal', que abrazaría por igual a todos los habitantes" (2005, p. 3).

Casi un siglo después, esta idea pierde progresivamente legitimidad. La tradición igualitaria del sistema educativo comenzó a ser cuestionada, especialmente por investigaciones que comprobaron los efectos desiguales de una escuela homogeneizadora, de estructura burocrática, y con un modelo de gestión pedagógica autoritaria. Según Dussel cuando finaliza la última dictadura militar en Argentina, las marcas autoritarias de esa forma escolar se hicieron visibles, en especial, en la educación secundaria, nivel que sufrió significativos cambios pedagógicos y curriculares en la transición democrática. Sin embargo, fue en la década del noventa, como veremos, que se impugnará con mayor radicalidad la idea de igualdad.

Aguilar Nery sostiene que durante cien años, la concepción de escuela igualitaria y el principio de igualdad de oportunidades fueron hegemónicos en el campo educativo argentino. A su entender, esto explicaría la aparición tardía del concepto de justicia educativa en la política pública y en la investigación educativa (AGUILAR NERY, 2015). Subyace en esta hipótesis un supuesto, compartido por otras investigaciones, que asocia la emergencia de la idea de justicia social a contextos de 
profunda fragmentación social y, paradójicamente, de fuerte devaluación de la idea de igualdad. De este modo, como se analizará, las nociones de justicia e igualdad dejan de complementarse, en el sentido clásico moderno que le asignara Rousseau, entre otros.

Con el retorno de la democracia en 1983 se lleva adelante la normalización de la vida universitaria. El regreso de las actividades académicas impulsó que en el ámbito de las Ciencias de la Educación se comenzara a desarrollar estudios de diagnóstico del sistema educativo argentino (BRASLAVSKY, 1985; NASSIF; TEDESCO; RAMA, 1984). Estas investigaciones concluyen que el sistema educativo, lejos de hacer efectiva la proclama de la escuela igualitaria, discrimina a grandes sectores de la población, básicamente ofreciendo una distribución desigual de saberes socialmente significativos. Estudios emblemáticos de esta época denunciaban nuevas formas de desigualdad fruto de la discriminación educativa, o incluso, una “escuela vacía” de conocimientos (BRASLAVSKY, 1985; TENTI FANFANI, 1993).

Así, Braslavsky utiliza el concepto de segmentación educativa para dar cuenta de la creciente diferenciación de recursos humanos, materiales y pedagógicos en la escuela primaria y secundaria, conformándose circuitos educativos diferenciados de calidad por los que transitaban alumnos de distintos niveles sociales. Lejos de la supuesta homogeneidad del sistema escolar, la investigación educativa muestra la existencia de trayectos diferenciados, estratificados socialmente, en cuando a las posibilidades de acumulación de capital cultural.

En este marco, al tiempo que académicos y actores políticos concentraban sus esfuerzos en lograr la democratización efectiva del sistema escolar, la idea de igualdad como principio normativo mostraba su limitación fáctica. No es casual, entonces, que en paralelo se empiece a cuestionar teóricamente el principio de igualdad de oportunidades y progresivamente sea reemplazado por la noción de equidad. Gran parte de los estudios pedagógicos de la época proponen, para compensar estas deficiencias, atender a formas de distribución más equitativa de los conocimientos socialmente significativos.

Esta transición conceptual acompañará el pasaje a la década de los noventa, donde el nuevo significante será el catalizador tanto de los esfuerzos académicos por democratizar el sistema educativo, como de una política educativa que realizaba un viraje teórico político. Y es que la noción de equidad coronó una mirada política y pedagógica donde la educación es definida como un bien social o una mercancía; de allí que importaba cómo distribuirla con criterios, no ya de justicia igualitaria, sino de equidad en la diversidad social, económica y cultural de los puntos de partida de las trayectorias escolares. 
En una entrevista publicada en el primer número de la Revista Propuesta Educativa, editada por FLACSO en el año 1989, Germán Rama habla de la naturaleza utópica de la idea de igualdad al tiempo que manifiesta su desconfianza en los siguientes términos:

La igualdad es uno de los anhelos permanentes de las sociedades humanas [...] Pero en la noción de igualdad yo no creo '[...] En ese mundo de competencia va a ser cada vez más difícil el planteo de la igualdad porque se vive en sociedades diferenciadas, en las que el conocimiento, la imposibilidad o no del conocimiento, los grados de conocimiento, son una forma de estratificación, y hay muchas otras (RAMA, 1989, p. 85).

Si bien en su crítica a la idea de igualdad se entremezclan argumentos biológicos (físicamente no somos iguales) e histórico sociales (estratificación social, cultural y económica) es llamativo en su planteo cómo la idea de igualdad, que es un concepto filosófico político, es analizada e impugnada en términos empíricos. Al estar emparentada a la no diferenciación, sería una opción más justa y democrática cambiarla por la noción de equidad:

Con esto quiero decir que, aun suponiendo una sociedad más justa, la igualdad no existiría. El problema, entonces, es el de la equidad. El punto es que no existan grupos que no tengan ciertos derechos mínimos, que no participen del zócalo común, la base común de la mastaba, a partir de la cual se construyen edificios sociales (RAMA, 1989, p. 86).

Y más adelante corona: "El gran tema de la educación latinoamericana es que su desarrollo fue un intento de establecer igualdad de oportunidades, vía educación, en sociedades altamente desiguales" (RAMA, 1989, p. 86). Así, desde organismos como CEPAL-Unesco comienzan a difundirse documentos que postulan para la región un desarrollo educativo con equidad.

Haciéndose eco de los estudios sobre las implicancias de la desigualdad en las esferas de la vida social, también la investigación educativa realizada fundamentalmente desde la FLACSO, realiza un diagnóstico sobre la trama de la desigualdad educativa en Argentina. A inicios del nuevo milenio, con niveles de pobreza, precarización y vulnerabilidad social altos, las investigaciones comienzan a constatar la fragmentación del sistema de escolar como una nueva forma de desigualdad educacional (TIRAMONTI, 2004; KESSLER, 2002). El nuevo concepto busca dar cuenta de un sistema escolar donde las desigualdades se han profundizado y cristalizado.

Según Tiramonti, la: 
[...] fragmentación resulta, en primer lugar, del aumento de la segmentación en el sistema educativo, donde las diferencias verticales entre escuelas se han cristalizado al punto de quebrarse una tradición normalista de formación homogénea de docentes: se generan demandas de perfiles y circuitos de reclutamiento diferenciados entre unas y otras instituciones. En segundo lugar, por la extensión de la lógica de individuación en la sociedad (TIRAMONTI, 2004, p. 27-28).

El pasaje de la segmentación a la fragmentación educativa es visto por Gabriel Kessler como un punto de inflexión conceptual en la caracterización del sistema educativo argentino (KESSLER, 2005, p. 852).

Frente a los efectos del neoliberalismo económico, la menor presencia del Estado en áreas sociales, la ruptura de la matriz estado céntrica (CAVAROZZI, 1996), se comprende por qué el concepto de justicia social vinculado al sector educativo haya sido instalado en el debate público y académico por las organizaciones sindicales. Mediando la década de los noventa, éste aparece en documentos técnicos y de formación política de la Confederación de Trabajadores de la Educación de la República Argentina (CTERA), y en gran parte de los diagnósticos y prospectivas que realiza el Instituto de Investigaciones Pedagógicas Marina Vilte (IIPMV), dependiente de la misma organización. La idea de justicia social emerge progresivamente, y con mayor fuerza con el cambio de siglo, tanto en el ámbito de la investigación educativa como en la gestión política, donde va a erigirse en uno de los principios fundamentales de las políticas públicas del período 2003-2015.

En un documento de CTERA del año 2004, donde se realiza un diagnóstico nacional de la desigualdad y exclusión educativa en la educación inicial, se alerta del estado de emergencia social y educativa al tiempo que se proponen lineamientos de acción política y pedagógica. Sin embargo, advierten que:

Estas políticas deben llevarse adelante en el marco de la revisión integral de la reforma educativa y de la necesaria reorganización del sistema educativo nacional. Y a la vez, realizarse en consonancia con políticas sociales, como el establecimiento de un ingreso ciudadano para la niñez y ayuda escolar universal para enfrentar la exclusión social de la mayor parte de nuestra infancia y adolescencia (IIPMV-CTERA, 2004, p. 18).

Para reforzar el enfoque teórico político desde el cual se realiza el diagnóstico y la prospectiva, los investigadores del IIPMV vuelven a trazar una fuerte vinculación entre justicia, igualdad y democratización de la educación. Esta perspectiva expresa una visión diferente en relación al marco normativo vigente para el sector educativo, pero también presenta una voz disidente en los estudios que, sobre la desigualdad y la justicia educativa, predominarán en algunos círculos académicos años después.

Así, el complemento necesario entre justicia e igualdad opera como criterio normativo desde donde la organización sindical realiza el diagnóstico de la situa- 
ción educativa y su consiguiente propuesta de transformación en dirección a la democratización de la educación escolar:

El grado de desigualdad que encontremos puede ser tomado como un indicador de "injusticia educativa”, donde a mayor desigualdad, mayor injusticia. Y por el contrario, a mayor igualdad, puede considerarse que existe - al menos en este aspecto - una mayor "democratización de la educación". Por exclusión educativa entenderemos, básicamente la negación del derecho a la educación, que en este caso - sobre todo en el de los niños de 5 años, comprendidos en la obligatoriedad de la sala de 5 años establecida por la Ley Federal de Educación -, será homologada con la imposibilidad de acceder a la educación inicial (IIPMV-CTERA, 2004, p. 1).

El mismo año, en el marco del debate sobre inclusión y exclusión en las escuelas, Inés Dussel propone tomar esta relación para pensar la injusticia social y educativa (DUSSEL, 2005, p. 331). A partir de ese momento, se suceden diferentes investigaciones que tendrán como eje de análisis la justicia social, en especial, relacionada con la inclusión educativa (KAPLAN; LLOMOVATTE, 2005; TEDESCO, 2008; 2010; 2012).

Para cerrar este breve recorrido, debemos mencionar que un nuevo hito lo constituye sin dudas, la Ley Nacional de Educación no 26.206 del año 2006. Resultado de un amplio debate y consulta a los actores sociales, políticos, académicos, sindicales y del propio sistema educativo, la nueva ley marca un cambio profundo en la forma de concebir la educación. De ser entendida como un bien social (Ley Federal de Educación n ${ }^{\circ}$ 24.195/1993) la educación pasa a definirse como un bien público y un derecho personal y social, garantizado por el Estado. ${ }^{2}$

El nuevo enfoque de la educación, como bien público y como derecho personal y social, se inscribe en una perspectiva política donde el desarrollo se sostiene con crecimiento económico y justicia social. Si la legislación anterior ponderaba la noción de equidad, ${ }^{3}$ haciéndose eco de aquello que emanaba de las usinas ideológicas de organismos internacionales y de lo producido por la investigación socioeducativa hegemónica de la época, la nueva Ley vuelve a instalar los conceptos de justicia, igualdad, bien común y solidaridad.

La idea de igualdad educativa y justicia social que consagra la ley será recuperada por múltiples programas socioeducativos que buscan combatir la exclusión social promoviendo la inclusión educativa en un espectro amplio, que no se circunscribe a la igualdad de oportunidades entendida como posibilidad de acceso a la escolaridad obligatoria. ${ }^{4}$

Siendo estos los antecedentes y el marco teórico normativo de la educación, pasaremos a analizar un modelo de justicia educativa, especialmente propuesto y diseñado para el sistema educativo de Argentina. 
b) La investigación educativa sobre temas de justicia e igualdad: criterios de redistribución y reconocimiento para la educación argentina.

Un estudio reciente y de amplia repercusión en el ámbito académico es el que, en octubre de 2011, publicaron investigadores del Programa de Educación de CIPPEC titulado La construcción de la justicia educativa. Criterios de redistribución y reconocimiento para la educación argentina. Los autores parten de la premisa que en la política educativa subyacen concepciones de justicia, de modo explícito o implícito, que suponen "modalidades de distribución de los recursos y valoración de los sujetos y grupos sociales" (VELEDA; RIVAS; MEZZADRA, 2011, p. 13). En este sentido, el trabajo se propone hacer "más conscientes esas decisiones, planteando criterios para un modelo de justicia educativa centrado en el contexto de la Argentina actual" (VELEDA; RIVAS; MEZZADRA, 2011, p. 13).

Luego de revisar los diferentes modelos de política educativa que organizaron la educación pública escolar, se preguntan "¿cuáles son las formas estructurales de combatir las desigualdades sociales desde el sistema educativo en la Argentina actual? ¿Qué criterios pueden guiar la construcción de la justicia educativa?" (VELEDA; RIVAS; MEZZADRA, 2011, p. 14). Además de tomar nota del registro con que se enmarca la justicia y la desigualdad, se introduce aquí un leitmotiv que recorre la obra. El mismo expresa que, lejos de ofrecer un modelo al cual adscribir, se proponen brindar herramientas conceptuales y principios para construir, democrática y colectivamente, una propuesta de justicia educativa viable y situada en el contexto argentino actual. Así, por ejemplo, puede leerse que:

Esta concepción de justicia no se propone como un modelo predefinido de un sistema educativo ideal, perfectamente justo. Al contrario, intenta señalar los criterios que podrían guiar a las políticas orientadas a limitar las injusticias del presente y posibilitar cambios concretos en el mundo real. De esta forma, planteamos un horizonte para la acción, una reflexión que abre dilemas y aporta caminos - no propuestas cerradas - para el planeamiento educativo (VELEDA; RIVAS; MEZZADRA, 2011, p. 15).

Las herramientas conceptuales y los criterios orientadores para la construcción de un modelo de justicia educativa son retomados de la filosofía política contemporánea, especialmente de las teorías de la justicia de John Rawls, Nancy Fraser y Amartya Sen; como así también de la sociología de la educación francesa, especialmente de François Dubet. Aquí sólo analizaremos la interpretación que realizan de la justicia social desde la Teoría Crítica, en especial, la interpretación y apropiación del debate que llevaron adelante Nancy Fraser y Axel Honneth.

Los autores reivindican el debate sobre la redistribución y el reconocimiento (FRASER; HONNETH, 2006) tomando ambos conceptos como "columna vertebral" del modelo de justicia que se proponen construir. Concretamente afirman, siguien- 
do a Fraser, "proponemos que los criterios para la mejora de la justicia educativa contemplen la dimensión de la redistribución de los bienes materiales o simbólicos, así como la dimensión del reconocimiento de los distintos contextos y tipos de actores" (VELEDA; RIVAS; MEZZADRA, 2011, p. 15).

Entienden que el abordaje político ${ }^{5}$ de las desigualdades educativas enfatizó la redistribución, por lo que se proponen conjugarla con "una revisión de los patrones institucionalizados de identificación, valoración e interacción del sistema educativo con los distintos tipos de actores sociales" (VELEDA; RIVAS; MEZZADRA, 2011, p. 15). Esta forma de comprender la categoría honnethiana les permite afirmar: "Sólo si reconocemos en todos los alumnos una igual dignidad y altas expectativas en sus posibilidades de acción, y se conocen de igual forma sus particularidades, podrán concebirse políticas tendientes a reducir las injusticias del sistema educativo" (VELEDA; RIVAS; MEZZADRA, 2011, p. 15).

Los principios orientadores sobre los cuáles se debe analizar y construir un modelo de justicia educativa que pretenda erigirse como cuarta vía, esto es, el abordaje social y político del sistema educativo, ${ }^{6}$ son los siguientes:

1. El principio universalista de la concepción de la educación como derecho humano, que rechaza las aproximaciones basadas en la educación como mérito, mercancía o don.

2. El principio revisionista de la audiencia "modelo" del sistema educativo (las clases medias y altas), que propicia que los sujetos populares sean parte del centro orgánico del sistema en lugar de ser atendidos en los márgenes por las políticas compensatorias.

3. El principio de correspondencia entre las concepciones basadas en la redistribución y el reconocimiento, como dos caras de influencia mutua en el camino hacia la justicia educativa.

4. El principio de las capacidades de acción en libertad como fin último del sistema educativo en reemplazo de las concepciones utilitarias - centradas en la calidad - o meritocráticas - centradas en la "igualdad de oportunidades".

5. El principio de contextualización, basado en la idea de justicia "comparativa", que no espera por un modelo ideal de justicia sino que busca dar pasos concretos en un contexto situado históricamente.

6. El principio de concientización de la política educativa, que propone una práctica reflexiva y autocrítica de las autoridades educativas sobre los obstáculos a la justicia propios de la organización estatal de la gestión de la educación.

7. El principio de participación social como parte de una mirada de la construcción de la justicia educativa que no va de arriba hacia abajo, sino que se logra en articulación, con diálogos democráticos entre los diversos actores sociales. 
Observaremos, por razones de espacio, sólo las precisiones teóricas que realizan sobre la igualdad y la justicia, en relación al modelo que se proponen construir.

Respecto a la igualdad, es claro el posicionamiento en relación a la crítica que hace Dubet, entre otros, a las dos grandes concepciones de justicia social centradas en la igualdad de oportunidades y la de posiciones (DUBET, 2011, 2015a; 2015b). $\mathrm{El}$ argumento sostiene que detrás de la igualdad de oportunidades y tratamiento de los alumnos, se ocultan formas de clasificación educativa originadas en la estructura social. Así, la escuela legitima las desigualdades al presentarlas como justas, porque las muestra como el resultado del mérito individual y no de las ventajas sociales externas a ella.

En términos fácticos los autores constatan que, más allá de la proclama igualitarista y homogeneizadora, la escuela no es indiferente a las diferencias que se derivan de las desigualdades sociales, sino que las profundiza en su hacer pedagógico (VELEDA; RIVAS; MEZZADRA, 2011, p. 61). Sin embargo, cuando se propone colocar a los sectores populares en el centro del sistema educativo, este criterio no:

supone concebir escuelas específicas para pobres. Al contrario, este paradigma de justicia aspira a fortalecer la educación pública como un espacio para todos, donde sea posible el encuentro de la diversidad, la reconstrucción de los lazos sociales y la recuperación de inscripciones culturales comunes, que unan y amparen a individuos diferentes" (VELEDA; RIVAS; MEZZADRA, 2011, p. 61).

Para fundamentar esta posición, recuperan y licúan la noción de paridad participativa la cual al no ser formulada en el marco de las escalas de justicia, pierde la potencialidad normativa y la radicalidad democrática de su sentido originario. Entienden que un modelo de justicia educativa deberá atender, de modo integral, las condiciones de paridad participativa de los sectores populares:

Se trata, en definitiva, de que los alumnos de sectores más postergados puedan participar en condiciones de paridad integral en la escolarización. Con este objetivo, la revisión del sistema educativo debería basarse en una doble concepción de la justicia educativa, que contemple a la vez las condiciones objetivas e intersubjetivas de la paridad participativa (Fraser, 2006) (VELEDA; RIVAS; MEZZADRA, 2011, p. 61).

Es llamativo que el modelo de justicia a construir sea bidimensional y se omita la dimensión política, justamente, ámbito en el cuál la educación pública argentina fue objeto de disputa desde sus inicios, como se mostró en el breve recorrido histórico. Nancy Fraser postula una concepción tripartita de justicia, que aún no estaba presente en el debate con Honneth, y sometida a un principio normativo general, la paridad participativa (FRASER, 2008). Además de la redistribución, que opera en el orden de la asignación de los recursos materiales, el reconocimiento, propio del orden cultural y la construcción de estatus, la tercera dimensión de la justicia es la 
política y tiene que ver con la representación de la pertenencia social y los procedimientos que las generan y dinamizan. Si bien la distribución y el reconocimiento están atravesados por lo político, en el sentido que están sujetos a las luchas y a la puja de poderes, Fraser precisa el concepto de la siguiente manera:

Pero yo entiendo lo político en un sentido más específico y constitutivo, que remite a la naturaleza de la jurisdicción del Estado y a las reglas de decisión con las que se estructura la confrontación. Lo político, en este sentido, suministra el escenario donde se desarrollan las luchas por la distribución y el reconocimiento. Al establecer los criterios de pertenencia social, y al determinar así quién cuenta como miembro, la dimensión política de la justicia especifica el alcance de las otras dimensiones: nos dice quién está incluido en y quién excluido del círculo de los que tienen derecho a una justa distribución y al reconocimiento mutuo. Al establecer las reglas de decisión, la dimensión política establece también los procedimientos para escenificar y resolver los conflictos en las otras dos dimensiones, la económica y la social: nos dice no sólo quién puede reivindicar redistribución y reconocimiento, sino también cómo han de plantearse y arbitrarse esas realizaciones (FRASER, 2008, p. 41).

La injusticia que se expresa en este tercer nivel es la representación fallida, la misma ocurre cuando los límites de lo político y/o las reglas de decisión funcionan injustamente al negar la posibilidad de participar en paridad en las interacciones sociales generadas en los ámbitos económico, cultural y político. La particularidad de esta dimensión es que establece el horizonte de posibilidad, al tiempo que traza la gramática de la distribución y el reconocimiento. Pero además, es la única dimensión de la justicia capaz de cuestionar el propio enmarque, esto es, cuando la representación fallida adopta una forma más profunda, metapolítica, y expresa una injusta delimitación del marco (misframing). Como se puede inferir, el enmarque, la dimensión política de la justicia, ofrece un potencial emancipador en tanto es el único capaz de revisar y modificar las reivindicaciones de justicia de primer orden. Así lo expresa Nancy Fraser: "la consecuencia es un tipo especial de metainjusticia, que niega a estos mismos la oportunidad de presionar con reivindicaciones de justicia de primer orden en una determinada comunidad política" (FRASER, 2008, p. 45).

También en el tercer principio que orienta la construcción del modelo, Veleda, Rivas y Mezadra vuelven a efectuar una particular lectura de la teoría de la justicia, al plantear la correspondencia entre las concepciones basadas en la redistribución y el reconocimiento, como dos caras de influencia mutua en el camino hacia la justicia educativa como cuarta vía.

Entienden que la política educativa se ha centrado mayormente en la redistribución, como forma de compensar las desigualdades materiales que se manifiestan en la escuela, en detrimento del reconocimiento, que no es suficientemente explorado. En la dimensión de la redistribución, las injusticias educativas están ligadas 
a las condiciones objetivas de vida de los alumnos. Afirman que "Los problemas eminentemente redistributivos se hacen patentes, por ejemplo, en el desigual acceso al bienestar de los hogares o en la desigualdad de condiciones de aprendizaje en las escuelas, o en los desiguales logros educativos de los alumnos" (VELEDA; RIVAS; MEZZADRA, 2011, p. 63).

A esto debe sumarse la esfera del reconocimiento. En esta dimensión, que opera en el orden de lo simbólico cultural las injusticias se derivan del orden de estatus social y "consisten en el menor respeto, estima y prestigio de ciertos grupos en comparación con otros". Inmediatamente aclaran que "El reconocimiento no se refiere a actitudes individuales que puedan dañar la autoestima de los sujetos, sino a 'patrones institucionalizados de valor cultural' que suelen considerar como normativas ciertas categorías de actores sociales y como inferiores a otras (Fraser, 2006)" (VELEDA; RIVAS; MEZZADRA, 2011, p. 20).

En el sistema educativo operan "patrones institucionalizados de valoración" por lo que es posible encontrar problemas de reconocimiento, vinculados con la invisibilización o la desvalorización de los rasgos distintivos de ciertos sectores sociales, grupos y colectivos específicos (VELEDA; RIVAS; MEZZADRA, 2011, p. 63).

Por esto, concluyen, un modelo de justicia educativa que atienda la complejidad de la problemática exige considerar tanto la dimensión de la redistribución como la del reconocimiento, es decir, que integre la redistribución económica con el "reconocimiento de la diversidad de contextos y culturas".

Al combinar los principios orientadores en la construcción de un modelo de justicia educativa, los autores se van a centrar en las condiciones materiales y pedagógicas que afectan los procesos de aprendizajes, atravesados por la distribución económica y el reconocimiento de las diversidades culturales. Así por ejemplo se analiza desde el tipo de alimentación que deben brindar los comedores escolares, como forma compensatoria de la exclusión social, hasta cómo superar el reconocimiento estigmatizante que sufren los niños que asisten a él.

Tal vez como parte del esfuerzo deliberado y recurrente por escapar a definiciones apriorísticas, al momento de situar y contextualizar la noción de justicia educativa, los autores encuentran una expresión más ajustada a sus expectativas, la de justicia curricular:

Como lo plantea Connel: "la justicia no se puede alcanzar mediante la distribución de la misma cantidad de un bien estándar a todos los niños de todas las clases sociales. [...] la justicia distributiva es una forma incompleta de entender las cuestiones educativas. Necesitamos un concepto distinto, al que llamaré justicia curricular" (Connel, 1997: 28). En efecto, la garantía de acceso a una cultura compartida exige aunar la dimensión de la redistribución con la del reconocimiento de la diversidad, tanto en la definición de los aprendizajes prioritarios, como en las modalidades de transmisión (VELEDA; RIVAS; MEZZADRA, 2011, p. 139). 
Es aquí donde el modelo de justicia se licúa, pierde gran parte de su potencialidad práctica porque fue desligado de su horizonte normativo y termina, por tanto, instrumentalizando las dimensiones de la teoría de la justicia e ignorando la cuestión de las escalas. Toda la lectura pedagógica que de aquí se deriva, camina errante entre figuras de dudosa novedad como lo es la crítica al currículum compartido y la propuesta de modelos de organización institucional flexibles, o bien recurren a fórmulas temerarias, como la que dictamina que el "formato escolar es la frontera de justicia", o de un optimismo ingenuo y voluntarista que hace del docente la pieza clave, y por momentos exclusiva, de la justicia educativa.

La falta de una concepción clara de lo que se entiende por justicia educativa no puede excusarse en la renuncia a la sustantivación; aun cuando la justicia se defina como una cuestión procedimental o un principio normativo radical, la teoría de la justicia se mueve en la tensión entre la facticidad y la normatividad.

En este sentido, la insistencia en no brindar un modelo ideal de justicia, sino "dar pasos concretos en un contexto situado históricamente", lo que al parecer es la mayor virtud del modelo, termina por ser su falencia estructural. Quizás la ligera identificación entre sustancia e idea explique el equívoco al afirmar que "el contenido de la justicia no puede ser establecido a través de principios fundacionales definidos de antemano para todas las situaciones" (VELEDA; RIVAS; MEZZADRA, 2011, p. 37). Si cada decisión y cada política supone criterios de justicia, la "construcción de una mayor justicia educativa debe basarse ante todo en una concientización de la política, es decir, en una reflexión y una explicitación de los criterios de justicia que cada política encarna" (VELEDA; RIVAS; MEZZADRA, 2011, p. 37). Pero aquí se impone preguntar desde dónde se legitima y construye "mayor justicia educativa", qué expresa, quiénes son sus potenciales afectados, cómo se dirimen las disputas y se modifican sus límites.

Por último, los autores recurren a Amartya Sen para diferenciar entre mejorar la justicia, dando pasos para superar las injusticias, y ofrecer respuestas a las preguntas sobre la naturaleza de la justicia perfecta. Aún decididos a no partir de definiciones sobre una escuela idealmente justa, sin embargo necesitan aclarar que "esto no implica pasar a un enfoque fragmentario sin sustentos teóricos, sino operar con las definiciones teóricas en la vida real” (VELEDA; RIVAS; MEZZADRA, 2011, p. 67). La cuestión es nuevamente, de dónde se extraen esas definiciones teóricas de justicia, cómo se construyen y se legitima su contenido, qué expresan y a quiénes, cuál es el límite y las posibilidades de modificación del propio enmarque.

Esto nos lleva a considerar un último tema desde la perspectiva de Teoría Crítica, esto es, la posibilidad de una concepción normativa, no metafísica, y anclada en la dinámica de los procesos sociales de injusticia. 


\section{Reconstrucción del lazo entre teoría normativa y ciencia social desde la Teoría Crítica}

Uno de los rasgos que distinguen el modelo de Teoría Crítica es la ponderación de la teoría social como hermenéutica crítica con potencialidad emancipatoria. Esto la diferencia de otros enfoques postmetafísicos que, aún asumiendo el giro pragmático lingüístico, conciben el rol de la filosofía como metateoría. Por el contrario, es necesario un abordaje teórico que no sacrifique la normatividad al tiempo que mantenga su inscripción en las prácticas sociales. En términos de Teoría Crítica, se trata de reconstruir la tensión entre la facticidad y normatividad como operador teórico que permita realizar la doble tarea, esto es, identificar los potenciales de emancipación actuantes en la realidad social e incorporar al diagnóstico del tiempo presente, los resultados de investigaciones que provienen de enfoques no críticos (NOBRE; REPA, 2012).

Habermas recuperó un camino productivo de cooperación entre teoría social y filosofía como procedimiento reconstructivo de una tradición que, al estar adscripta a la filosofía de la conciencia y a un modelo de racionalidad cognitivo instrumental, había obturado el potencial emancipatorio de la Ilustración. Cuando la filosofía abandona la función de guardiana de la razón y acomodadora del conocimiento de las ciencias (HABERMAS, 2008) se abre a buscar en lo preteorético formas de legitimidad que permitan rehabilitar la crítica y detectar indicios de emancipación. Las ciencias crítico-hermenéuticas primero, la Teoría de la Sociedad y luego el Derecho, fueron protagonistas de esta empresa reconstructiva; pero también de un modo de trabajo interdisciplinario donde la investigación científica, las ciencias sociales y la filosofía confluían y aportaban a la interpretación del presente histórico. En su caso particular, la noción de mundo de la vida (Lebenswelt) muestra esa apertura y aún hoy representa un campo prolífico de interpretación, indagación y construcción conceptual para las Ciencias de la Educación.

También Honneth reconoce el déficit sociológico de la Teoría Crítica y hace de esto, uno de los condimentos de su teoría reconstructiva. Así como al inicio de este artículo expresábamos la reticencia de la investigación educativa en relación a la filosofía, ocurre algo parecido en la dirección contraria. Expresa este autor que "una de las limitaciones de la filosofía política actual es estar desacoplada del análisis de la sociedad y, por lo tanto, fijada en principios puramente normativos" (HONNETH, 2014, p. 13). Más que recusarse mutuamente, el desafío será pensar un modelo donde ambos se complementen porque, así como al sacrificar la normatividad se corre el riesgo de fetichizar la empiricidad, una normatividad no anclada en la dinámica social del presente resiente su potencialidad emancipatoria. La apuesta de la Teoría Crítica es compleja, se propone superar el déficit sociológico 
de la filosofía, al tiempo que busca reconstruir normativamente la facticidad moral inscripta en las prácticas sociales.

Como se expuso, el modelo de justicia educativa desarrollado por Veleda, Rivas y Mezzadra presenta una lectura particular de la Teoría Crítica de la justicia de Fraser. En esa interpretación, había dos elementos que fueron subrayados. Por un lado, la negación a adoptar un modelo normativo de justicia ideal, apriorístico según el sentido que parecen otorgarle los autores. En segundo lugar, al omitir la dimensión política de la justicia, el debate sobre el enmarque y las escalas de justicia queda neutralizado. Frente a esto, quisiéramos traer a colación el planteo originario de la autora, para demostrar cómo opera la tensión entre normatividad y conocimiento empírico como dispositivo crítico.

Nancy Fraser muestra los límites y las consecuencias prácticas, performativas, del enmarque, en especial cuando éste da cuenta de un modelo de normalidad que ha quedado rebasado. Precisamente es en tiempos de justicia anormal ${ }^{7}$ donde florece e interpela con fuerza aquello que denomina los dos dogmas del igualitarismo. ${ }^{8}$ Consideraremos aquí el segundo, para introducir la relación entre ciencia social y teoría normativa.

El segundo dogma del igualitarismo consiste en suponer de forma tácita que la ciencia social normal puede determinar el quién de la justicia:

Me interesa dirigir la atención hacia la manera irreflexiva con la que entra en los debates actuales un particular punto de vista sobre la relación entre teoría normativa y ciencia social. En la medida que los filósofos dan simplemente por supuesto este punto de vista, dejan de someter a reflexión crítica la cuestión del procedimiento. Dejan de preguntarse de una manera metodológicamente autorreflexiva cómo debería determinarse el marco pertinente para reflexionar sobre la justicia social en un mundo en globalización, qué criterio o qué procedimiento de decisión debería invocarse y quién es a la postre el que tendría que decidir (FRASER, 2008, p. 78).

La investigación presentada, en su intento de no sustancializar un concepto de justicia educativa, tampoco da cuenta del marco en que la misma es analizada. Así, la justicia es un principio normativo establecido convencionalmente asociado a la igualdad, en el marco de los fundamentos normativos del Estado de derecho, pero también un indicador empírico sobre el cuál la investigación puede proclamar, escuetamente, su presencia o ausencia, a quienes beneficia o perjudica y de qué manera. Sin embargo, se diluye y trasmuta el marco desde dónde se problematiza la justicia; la densidad, el peso específico que impone el marco hace que la respuesta a lo anterior varíe considerablemente. No es lo mismo decir que la injusticia educativa tienen una matriz económico social, y por ende es expresión de la desigual distribución de la riqueza y de los bienes culturales, a nominar de este modo la multiplicidad de subjetivaciones que conjugan una clase escolar; aquí lo "injusto 
y desigual" es el reflejo de la diversidad inherente a las sociedades complejas, un rasgo propio del presente que legítimamente pondera por expresarse.

Considerar estos marcos como equivalentes, o al menos no guardar la suficiente autorreflexión sobre ellos, tiene un efecto performativo. Estas consecuencias crecen exponencialmente si se considera la espesura práctica de la educación y el sentido de la investigación educativa, asociada de forma mediata o inmediata, a la intervención y transformación de las prácticas pedagógicas.

El tema a debatir es, entonces, el que la propia modernidad inauguró: la legitimidad, el autocercioramiento crítico del conocimiento y sus formas de producción. También en los albores de la modernidad, se constató la ausencia de justicia y de igualdad; incluso hubiese sido posible confirmar que, de hecho, "las sociedades parecían preferir la desigualdad". Del mismo modo, encontraríamos reparos metodológicos y construcciones argumentativas sobre la relación entre normatividad y facticidad. Así Rousseau y Kant, con matices diferentes, se detienen extensamente al momento de justificar la vinculación entre los principios que establecen sus respectivas filosofías de la historia, y la historia como acontecimiento fenoménico. También ellos advirtieron las consecuencias de pensar el lazo entre ambas dimensiones, o incluso, de su desgajamiento. ${ }^{9}$ Es esto último lo que determinó con fuerza sus teorías y lo que marca la distancia con algunos debates actuales. Sin contar con el desarrollo de la ciencia social, y aún desde una concepción filosófica que hoy nos resultaría incómoda adoptar, esto no impidió que impulsaran diagnósticos epocales de tinte crítico e identificaran en ellos una dirección emancipatoria. No es el contenido o la forma de sus concepciones lo que quisiéramos recuperar aquí, sino confrontar con ellos para comprender la operación teórico- metodológica que hoy nos impide rehabilitar el lazo entre teoría normativa y ciencia social crítica.

El vínculo entre la empiricidad objetivada en la investigación y las definiciones normativas del enmarque no se agotan en las creencias, valores y principios de los investigadores, las instituciones o los movimientos sociales. Hacer explícitos esos principios, por vía reflexiva y como recaudo metodológico tal como lo propone Dubet (2015a, p. 230) no garantiza la crítica, en el sentido emancipador e inmanente. En esta dirección, Fraser lo expresa de la siguiente manera:

El hecho empírico de quién está afectado, lejos de ser independiente, es un artefacto performativo de diseño anterior. Apelar a la ciencia normal para determinar el quién en esos casos no es introducir consideraciones epistémicas independientes. Es más bien ratificar acríticamente una decisión previa sobre marcos (2008, p. 85).

Con todo, la investigación empírica al revestirse de objetivismo fáctico no sólo legitima acríticamente el enmarque, no lo problematiza, sino que introduce otra operación teórica de consecuencias prácticas no ponderadas, cuando apela a las 
condiciones de producción de la justicia social como límite de posibilidad. Bajo un aggiornado determinismo de las circunstancias, se licúa el potencial transformador y se dificulta la posibilidad de crítica frente al peso de los hechos. En este sentido, es llamativo cómo en las investigaciones que estudian la desigualdad social, a la que asocian la producción de injusticia educativa, subyace esta mecánica de análisis en sus diagnósticos sobre distribución y reconocimiento, y sobre todo, en las estrategias de intervención. Con claridad lo refiere nuevamente la autora que es tomada como referente teórico de esas mismas investigaciones: "No podemos fijar debates sobre el quien apelando a las circunstancias de la justicia, como si esto fuera simplemente asunto de hechos empíricos indiscutibles" (FRASER, 2008, p. 82).

Por esto, aunque la investigación educativa se autoproclame crítica, su rechazo al normativismo la coloca en una posición cercana al cientificismo propio de una teoría tradicional. La parcialidad asume la forma de lo empíricamente dado, controlado y objetivado como hecho social. Esta presunción cientificista está detrás de la certeza que son:

hechos incontrovertidos los que indican quién está afectado y por qué cosa. Sin embargo, en la justicia anormal las disputas sobre el marco no son reducibles a simples cuestiones de carácter empírico, ya que las interpretaciones históricas, las teorías sociales y los supuestos normativos, que necesariamente subyacen en las reivindicaciones fácticas, están también sometidos a discusión. Adoptar presunciones cientificistas es arriesgarse a impedir de entrada las reivindicaciones de los desfavorecidos (FRASER, 2008, p. 131).

El horizonte emancipatorio está vinculado al carácter normativo de la Teoría Crítica. La ausencia de una perspectiva normativa resiente la posibilidad de obrar reflexiva y críticamente sobre el propio encuadre. Precisábamos en el apartado anterior cómo las investigaciones sobre justicia educativa, al recuperar las escalas olvidaban la dimensión política de la justicia social. En términos de Teoría Crítica, con esto se limita su eficacia práctica; la teoría no es un instrumento capaz de medir indicadores que ella misma produce. Como recuerda Demirović (2005), la teoría es la forma en la que el pensar, surgido de un hacer, adopta una figura para pronunciar y direccionar el mundo al que está adscripto. No se trata tanto de explicitar los supuestos normativos de las decisiones metodológicas, en el sentido de la teoría tradicional, sino cómo el conocimiento producido muestra su eficacia política al desmontar la gramática de la injusticia social.

Si algo ha legado la Teoría Crítica, especialmente a partir del giro intersubjetivo, es que el punto de vista crítico no puede colocarse a costa de los actores sociales, sea bajo la forma de conocimiento científico o como expresión de una vanguardia política (CELIKATES, 2012). El desafío será construir, en el campo educativo, perspectivas teóricas que recojan las estructuras normativas inscriptas en el mundo de 
la vida, elaboren su formalización crítica y prueben su eficacia política. Para esto, es necesario que la filosofía y la investigación educativa recuperen y actualicen el lazo complementario que las une. Parafraseando a Honneth, tal vez sea éste el momento donde ambas necesiten volver a reconocerse como hermanas.

\section{Normativity, justice and education. Concerning the relationship between philosophy of education and educational research}

Abstract

The link between philosophy of education and educational research hasn't been debated. In the educational sciences, it was raised either in antagonistic terms, or assuming the philosophy the task of basing the empirical knowledge of sciences. From Critical Theory it's necessary reconstruct the link among normative theory and social science, especially when it's a practical object as the education. The analysis will focus in the debate on the social justice in education, because it involve the production of knowledges of the educational research with normative definitions of the political philosophy. Finally, we will confront this perspective with studies on educational justice recently realized in Argentina. These studies refer to authors and discussions of Critical Theory. However, this analysis doesn't apply that perspective, especially by how the relationship between normativity and production of academic knowledge is built.

Keywords: Normativity. Justice. Critical theory. Philosophy of education. Educational research.

\section{Notas}

1 Los autores ensayan el mismo recorrido pero considerando los modelos de política educativa, centrado en la relación estado-sociedad. Así diferencian: 1) modelo aula desdoblado (1884-1930); 2) modelo expansivo sistémico (1930-1990); 3) modelo compensatorio dual (1990-2006). El cuarto modelo, a construir, el de justicia educativa, es la prospectiva y desafío que tiene la política educativa si pretende transformar realmente e incidir en la realidad (Cfr. VELEDA; RIVAS; MEZZADRA, 2011, p. 24-32).

2 No podemos dejar de asociar el planteo de Hannah Arendt al diferenciar la educación como bien social o como bien público; lo que se dirime en el fondo es concebirla como una mercancía o como un derecho. Recuerda la autora que el auge de lo social coincidió históricamente con la transformación del interés privado por la propiedad en un interés público: "La sociedad, cuando entró por vez primera en la esfera pública, adoptó el disfraz de una organización de propietarios que, en lugar de exigir el acceso a la esfera pública debido a su riqueza, pidió protección para acumular más riqueza" (ARENDT, 2003, p. 73).

3 Es sintomático que la Ley Federal de Educación coloque reiteradamente la idea de equidad frente a la de igualdad, y que se reserve la expresión de justicia social a un único artículo, como principio de justicia distributiva, para referirse a la subvención estatal de la educación privada: "Artículo 37 - El aporte estatal para atender los salarios docentes de los establecimientos educativos de gestión privada, se basara en criterios objetivos de acuerdo al principio de justicia distributiva en el marco de la Justicia Social y teniendo en cuenta entre otros aspectos; la función social que cumple en su zona de influencia, el tipo de establecimiento y la cuota que se percibe" (Ley Federal de Educación no 24.195/1993, art. 37, inc. 6, 2003).

4 Ejemplos de esto son el programa Conectar Igualdad creado en abril de 2010 (Decreto PEN nº 459/2010) bajo la órbita del Ministerio de Educación de la Nación y la Asignación Universal por Hijo (Decreto PEN n⿳0 $1602 / 2009$ y posteriormente Ley no $24.714 / 2015$ ).

5 Por abordaje político se refieren al modo en que la gestión política de la educación intervino en relación a las desigualdades sociales como formas de injusticia. Como se mostrará, los autores no hacen referencia a la dimensión política de la justicia social. 
6 A diferencia de las tres vías adoptadas por la política educativa, que van de la homogeneidad a la compensación, la cuarta vía a construir es la de la justicia educativa.

7 Inspirada en la distinción que Richard Rorty hace entre discurso normal y anormal, Fraser observa que la justicia normal acontece cuando los conflictos, debates y confrontaciones comparten supuestos subyacentes y principios organizativos, es decir, adoptan una forma reconocible porque conllevan una gramática discernible. Sin embargo, la autora caracteriza el contexto actual como de justicia anormal porque proliferan debates públicos sobre la justicia que, aunque desestructurados, cuestionan la gramática de la justicia normal en relación al "qué", "quién” y "cómo" (FRASER, 2008).

8 El primer dogma del igualitarismo es la presuposición, asumida sin examen, del "quien” nacional en las reivindicaciones de justicia, es decir, suponer el marco keynesiano-westfaliano (FRASER, 2008).

9 Véase como ejemplo las condiciones que impone Kant al acontecimiento con valor de signo de progreso, o el sentido que la construcción teórica estado de naturaleza juega en la argumentación de Rousseau.

\section{Referencias}

AGUILAR NERY, J. Formación y desarrollo del concepto de justicia educativa en Argentina. Revista Internacional de Educación para la Justicia Social, Madrid, v. 4, n. 2, p. 127-143, 2015.

ARENDT, H. La condición humana. Buenos Aires: Paidós, 2003.

BRASLAVSKY, C. La discriminación educativa en Argentina. Buenos Aires: FLACSO-GEL, 1985 .

CAVAROZZI, M. Más allá de las transiciones a la democracia en América Latina. En El capitalismo político tardío y su crisis en América Latina. Rosario: Homo Sapiens, 1996.

CELIKATES, R. O não reconhecimento sistemático e a prática da crítica. Bourdieu, Boltanski e o papel da teoria crítica. Novos Estudos, São Paulo, n. 93, p. 29-42, 2012.

CULLEN, C. Perfiles ético-políticos de la educación. Buenos Aires: Paidós, 2004.

DEMIROVIĆ, A. Para una nueva formulación del saber crítico. Journal EIPCP, Transversal Texts, Viena, n. 12, 2005. Disponível em: <http://eipcp.net/transversal/0806/demirovic/es>.

DUBET, F. Los postulados normativos de la investigación educativa. Espacios en Blanco Revista de Educación, Buenos Aires, n. 25, p. 229-249, 2015a.

. ¿Por qué preferimos la desigualdad? Buenos Aires: Siglo XXI, 2015b.

. Repensar la justicia social: contra el mito de igualdad de oportunidades. Buenos Aires: Siglo XXI, 2011.

DUSSEL, I. Desigualdades sociales y desigualdades escolares en la Argentina de hoy. Algunas reflexiones y propuestas. En: TEDESCO, J. C. (Comp.). ¿ Cómo superar la desigualdad y la fragmentación del sistema educativo argentino? Buenos Aires: IIPE Unesco, 2005. p. 85-115.

FRASER, N. Escalas de justicia. Barcelona: Herder, 2008.

FLICKINGER, H. G. A dinâmica do conceito de formação (Bildung) na atualidade. En: CENCI, A.; DALBOSCO, C.; MüHL, E.; Sobre filosofia e educação. Racionalidade, diversidade e formação pedaógica. Passo Fundo: UPF Editora, 2009.

FRASER, N.; HONNETH, A. ¿Redistribución o reconocimiento? Un debate político-filosófico. Madrid: Morata, 2006. 
GOERGEN, P. Formação ontem e hoje. En: CENCI, A.; DALBOSCO, C.; MÜHL, E. (Org.). Sobre filosofia e educação: racionalidade, diversidade e formação pedagógica. Passo Fundo: UPF Editora, 2009. p. 25-63.

HABERMAS, J. Conciencia moral y acción comunicativa. Madrid: Trotta, 2008.

HONNETH, A. El derecho de la libertad: esbozo de una eticidad democrática. Buenos Aires: Katz, 2014.

. La educación y el espacio público democrático: un capítulo descuidado en la filosofía política. Isegoría - Revista de Filosofía Moral y Política, Madrid, n. 49, p. 377-395, 2013.

IIPMV-CTERA Desigualdad y exclusión educativa en la educación inicial. Informes y estudios sobre la situación educativa, Buenos Aires, n. 3, p. 1-24, 2004.

KAPLAN, C.; LLOMOVATTE, S. (Ed.). Desigualdad educativa: la naturaleza como pretexto. Buenos Aires: Centro de Publicaciones Educativas, 2005.

KESSLER, G. La experiencia escolar fragmentada: estudiantes y docentes en la escuela media en Buenos Aires. Buenos. Aires: IIPE Unesco, 2002.

KESSLER, G. Reseña de "La trama de desigualdad educativa. Mutaciones recientes en la escuela media" de Guillermina Tiramonti (comp.). Revista Mexicana de Investigación Educativa, México, D.F., v. 10, n. 26, p. 951-956, jul./sept. 2005.

NASSIF, R.; TEDESCO, J.; RAMA, G. El sistema educativo en América Latina. Buenos Aires: Kapeluz, 1984.

NOBRE, M.; REPA, L. Habermas e a reconstrução: sobre a categoria central da teoria crítica habermasiana. Campinas: Papirus, 2012.

PUIGGRÓS, A. Sujetos, disciplinas y currículum. Buenos Aires: Galerna, 1990.

RAMA, G. Igualdad: ¿una noción utópica? Propuesta Educativa, Buenos Aires, n. 1, p. 82-89, 1989.

SIMONS, M.; MASSCHELEIN, J. Defensa de la escuela: una cuestión pública. Buenos Aires: Miño y Dávila, 2014.

TEDESCO, J. Educación y sociedad en Argentina (1880-1945). Buenos Aires: Solar, 1986.

La Educación en el horizonte 2020. Educación y justicia en el sentido de la educación.

Buenos Aires: Editorial Santillana, 2008.

Educar para la justicia social. Nuevos proceso de socialización, ciudadanía y educación en América Latina. Revista del IIDH, v. 52, 2010.

J. Educación y justicia social en América Latina. Buenos Aires: FCE-UNSAM, 2012.

TENTI FANFANI, E. La escuela vacía. Buenos Aires: Losada - Unicef, 1993.

TIRAMONTI, G. La trama de la desigualdad educativa: mutaciones recientes en la escuela media. Buenos Aires: Manantial, 2004.

VELEDA, C.; RIVAS, A.; MEZZADRA, F. La construcción de la justicia educativa. Criterios de redistribución y reconocimiento para la educación argentina. Buenos Aires: CIPPEC - Unicef, 2011. 